\title{
Bertrand Competition with Asymmetric Costs: A Solution in Pure Strategies
}

Citation for published version (APA):

Demuynck, T., Herings, P. J-J., Saulle, R. D., \& Seel, C. (2018). Bertrand Competition with Asymmetric Costs: A Solution in Pure Strategies. Maastricht University, Graduate School of Business and Economics. GSBE Research Memoranda No. 002 https://doi.org/10.26481/umagsb.2018002

Document status and date:

Published: 08/02/2018

DOI:

10.26481/umagsb.2018002

Document Version:

Publisher's PDF, also known as Version of record

\section{Please check the document version of this publication:}

- A submitted manuscript is the version of the article upon submission and before peer-review. There can be important differences between the submitted version and the official published version of record.

People interested in the research are advised to contact the author for the final version of the publication, or visit the DOI to the publisher's website.

- The final author version and the galley proof are versions of the publication after peer review.

- The final published version features the final layout of the paper including the volume, issue and page numbers.

Link to publication

\footnotetext{
General rights rights.

- You may freely distribute the URL identifying the publication in the public portal. please follow below link for the End User Agreement:

www.umlib.nl/taverne-license

Take down policy

If you believe that this document breaches copyright please contact us at:

repository@maastrichtuniversity.nl

providing details and we will investigate your claim.
}

Copyright and moral rights for the publications made accessible in the public portal are retained by the authors and/or other copyright owners and it is a condition of accessing publications that users recognise and abide by the legal requirements associated with these

- Users may download and print one copy of any publication from the public portal for the purpose of private study or research.

- You may not further distribute the material or use it for any profit-making activity or commercial gain

If the publication is distributed under the terms of Article $25 \mathrm{fa}$ of the Dutch Copyright Act, indicated by the "Taverne" license above, 
Thomas Demuynck,

P. Jean-Jacques Herings,

Riccardo D. Saulle, Christian Seel

Bertrand Competition with Asymmetric Costs: A Solution in Pure Strategies

$\mathrm{RM} / 18 / 002$

\section{GSBE}

Maastricht University School of Business and Economics

Graduate School of Business and Economics

P.O Box 616

NL-6200 MD Maastricht

The Netherlands 


\title{
Bertrand Competition with Asymmetric Costs: A Solution in Pure Strategies
}

\author{
Thomas Demuynck * $^{*}$ P. Jean-Jacques Herings ${ }^{\dagger}$ Riccardo D. Saulle ${ }^{\ddagger}$ \\ Christian Seel $\S$ \\ February 1, 2018
}

\begin{abstract}
We consider two versions of a Bertrand duopoly with asymmetric costs and homogeneous goods. They differ in whether predatory pricing is allowed. For each version, we derive the Myopic Stable Set in pure strategies as introduced by Demuynck, Herings, Saulle, and Seel (2017). We contrast our prediction to the prediction of Nash Equilibrium in mixed strategies.
\end{abstract}

KEYWORDS: Bertrand Competition, Asymmetric Costs, Myopic Stable Set.

JEL classification: $C^{r} 7, C 72, D 43$.

\footnotetext{
*Ecares, Université Libre de Bruxelles, Belgium. E-Mail: Thomas.Demuynck@ulb.ac.be. Thomas Demuynck acknowledges financial support by the Fonds de la Recherche Scientifique-FNRS under grant nr F.4516.18

${ }^{\dagger}$ Department of Economics, Maastricht University, Maastricht, The Netherlands. E-Mail: P.Herings@maastrichtuniversity.nl

${ }^{\ddagger}$ Department of Economics, Maastricht University, Maastricht, The Netherlands. E-Mail: R.Saulle@maastrichtuniversity.nl

${ }^{\S}$ Department of Economics, Maastricht University, Maastricht, The Netherlands. E-Mail: C.Seel@maastrichtuniversity.nl
} 


\section{Introduction}

The analysis of price competition is a fundamental part of oligopoly theory since Bertrand's contribution (Bertrand, 1883). The Bertrand duopoly with symmetric constant marginal costs, homogeneous goods and continuous prices has a unique Nash Equilibrium characterized by a strategy profile in which prices equal marginal costs.

If marginal costs are not symmetric across firms and the market is shared if firms set equal prices, no pure strategy Nash equilibrium exists. Blume (2003) shows that there exists a Nash equilibrium in mixed strategies where the more efficient firm sets price equal to the opponent's marginal cost and serves the entire market with probability 1 . The rival randomizes uniformly on an interval above his marginal cost. Kartik (2011) strengthens this result by showing that all undominated equilibria have the same outcome in terms of market price and shares. When dominated strategies are allowed, no such result is known.

In this paper, we analyze two versions of the same Bertrand game, one in which predatory pricing (i.e. setting prices below marginal costs) is allowed and one in which predatory pricing is forbidden. Predatory prices correspond to dominated strategies. We use a solution concept recently introduced by Demuynck, Herings, Saulle, and Seel (2017), the Myopic Stable Set. A set of strategy profiles is myopically stable if it satisfies three conditions, deterrence of external deviations, asymptotic external stability and minimality. Deterrence of external deviations requires that no player benefits by switching her strategy such that the resulting strategy profile is outside the Myopic Stable Set. Asymptotic external stability makes sure that from any strategy profile outside the set it is possible to get arbitrarily close to a strategy profile inside the Myopic Stable Set by a sequence of better replies. The final condition, minimality, requires that the Myopic Stable Set is minimal with respect to set inclusion.

In Demuynck, Herings, Saulle, and Seel (2017) we defined the Myopic Stable Set for a very general class of social environments (Chwe, 1994) that allows for infinite state spaces and includes normal-form games as a special case. We proved that if the state space is compact then the myopic stable set exists and under some mild continuity assumptions it is also unique. Moreover, we showed that the Myopic Stable Set coincides with the set of pure strategy Nash Equilibria for supermodular games, aggregative games and potential games.

In light of these results, the Bertrand model with asymmetric costs is interesting for several reasons: it does not satisfy the compactness and continuity assumptions of Demuynck, Herings, Saulle, and Seel (2017), it does not belong to any of the aforementioned classes of games and the set of pure strategy Nash equilibria of this game is empty.

We prove existence and uniqueness of the Myopic Stable Set for asymmetric Bertrand competition and characterize the set, both when predatory pricing is allowed and when it is forbidden. 


\section{Model and Solution Concept}

In this section, we define the myopic stable set for normal-form games $G:=\left(N,\left(S_{i}\right)_{i \in N},\left(\pi_{i}\right)_{i \in N}\right)$, where $N=\{1, \ldots, n\}$ is a finite set of players with typical element $i, S_{i}$ is the set of strategies for each player $i \in N$ and $\pi_{i}: \times_{i \in N} S_{i} \rightarrow \mathbb{R}$ is the payoff function of player $i$. Denote the strategy space by $S=\times_{i \in N} S_{i} \subseteq \mathbb{R}^{n}$. We use the standard notation $s:=\left(s_{i}, s_{-i}\right) \in S$ to denote the strategy profile where $s_{-i}$ is the list of strategies of all players except $i$, i.e., $s_{-i}:=\left(s_{j}\right)_{j \in N \backslash\{i\}}$.

We say that a strategy profile $s^{\prime} \in S$ dominates another strategy profile $s \in S$ if there is a player who can unilaterally deviate to $s^{\prime}$ and strictly prefers $s^{\prime}$ over $s$, i.e., from $s$, the player has a better reply such that the resulting strategy profile is $s^{\prime}$.

Definition 1 (Dominance). Let $s, s^{\prime} \in S$ be two strategy profiles. The strategy profile $s^{\prime}$ dominates $s$ if there exists a player $i \in N$ such that $\pi_{i}\left(s^{\prime}\right)>\pi_{i}(s)$ and $s_{-i}^{\prime}=s_{-i}$.

Let some strategy profile $s \in S$ be given. The set of all strategy profiles that dominates $s$ together with $s$ itself is denoted by $f(s)$,

$$
f(s)=\{s\} \cup\left\{s^{\prime} \in S \mid s^{\prime} \text { dominates } s\right\} .
$$

We define the two-fold composition of $f$ by

$$
f^{2}(s)=\left\{s^{\prime \prime} \in S \mid \exists s^{\prime} \in S: s^{\prime} \in f(s) \text { and } s^{\prime \prime} \in f\left(s^{\prime}\right)\right\} .
$$

By induction, for $k \geqslant 3$, we can define the $k$-fold composition $f^{k}(s)$ by $s^{k} \in f^{k}(s)$ if there is $s^{k-1} \in f^{k-1}(s)$ such that $s^{k} \in f\left(s^{k-1}\right)$. Observe that for all $k, \ell \in \mathbb{N}$ such that $k \leqslant \ell$ it holds that $f^{k}(s) \subseteq f^{\ell}(s)$. We define the set of all strategy profiles that can be reached from $s$ by a finite number of dominations by $f^{\mathbb{N}}(s)$, where

$$
f^{\mathbb{N}}(s):=\bigcup_{k \in \mathbb{N}} f^{k}(s) .
$$

Given $s, s^{\prime} \in S$, we say that a strategy profile $s^{\prime}$ asymptotically dominates $s$ if starting from $s$, it is possible to get arbitrarily close to $s^{\prime}$ in a finite number of dominations. Let $d\left(s, s^{\prime}\right)$ denote the Euclidean distance between $s$ and $s^{\prime}$. The asymptotic dominance criterion is formally defined as follows:

Definition 2 (Asymptotic Dominance). A strategy profile $s^{\infty} \in S$ asymptotically dominates $s \in S$ if for all $\varepsilon>0$ there exists $s^{\prime} \in f^{\mathbb{N}}(s)$ such that $d\left(s^{\infty}, s^{\prime}\right)<\varepsilon$.

We denote the set of all strategy profiles in $S$ that asymptotically dominate $s$ by $f^{\infty}(s)$. Formally,

$$
f^{\infty}(s)=\left\{s^{\infty} \in S \mid \forall \varepsilon>0, \exists s^{\prime} \in f^{\mathbb{N}}(s): d\left(s^{\infty}, s^{\prime}\right)<\varepsilon\right\} .
$$


It is easy to see that the set $f^{\infty}(s)$ coincides with the closure of the set $f^{\mathbb{N}}(s)$. We are now ready to define the Myopic Stable Set, abbreviated as MSS, for normal-form games.

Definition 3 (Myopic Stable Set (MSS)). Let $G:=\left(N,\left(S_{i}\right)_{i \in N},\left(\pi_{i}\right)_{i \in N}\right)$ be a normal-form game. The set $M \subseteq S$ is a myopic stable set (MSS) if it is closed and satisfies the following three conditions:

1. Deterrence of external deviations: For all $s \in M, f(s) \subseteq M$.

2. Asymptotic external stability: For all $s \notin M, f^{\infty}(s) \cap M \neq \varnothing$.

3. Minimality: There is no closed set $M^{\prime} \subsetneq M$ that satisfies Conditions 1 and 2 .

Let $M$ be a MSS. Deterrence of external deviations requires that no player can profitably deviate to a strategy profile outside $M$. Asymptotic external stability requires that any strategy profile outside $M$ is asymptotically dominated by a strategy profile in $M$. Hence, from any strategy profile outside of $M$ it is possible to get arbitrary close to a strategy profile in $M$ by a finite number of dominations. Observe that an empty set would necessarily violate asymptotic external stability, so it follows that $M$ is non-empty.

\section{Bertrand Duopoly with Asymmetric Costs}

Consider a model with two firms, $N=\{1,2\}$, having constant marginal costs $0 \leqslant c_{1}<c_{2}$ and no fixed costs. The strategy space $P_{i}$ of a firm $i \in N$ consists of all non-negative prices, i.e., $P_{i}=[0, \infty)$. Define $P:=P_{1} \times P_{2}$ with typical element $p$.

The continuous market demand function $D:[0, \infty) \longrightarrow \mathbb{R}_{+}$expresses the demand for the good as a function of the lowest price $p_{\mathrm{m}}$ available in the market. There exists a "choke" price $\bar{p}_{\mathrm{m}} \in\left(c_{2}, \infty\right)$ such that $D\left(p_{\mathrm{m}}\right)=0$ for all $p_{\mathrm{m}} \geqslant \bar{p}_{\mathrm{m}}$. The demand is strictly decreasing on $\left[0, \bar{p}_{\mathrm{m}}\right]$ and zero on $\left[\bar{p}_{\mathrm{m}}, \infty\right)$. We assume that there is an $\varepsilon>0$ such that the profits $\left(p_{\mathrm{m}}-c_{1}\right) D\left(p_{\mathrm{m}}\right)$ of a monopolist with marginal costs $c_{1}$ are strictly increasing in $p_{\mathrm{m}}$ on the domain $\left[c_{1}, c_{2}+\varepsilon\right]$. This assumption ensures an element of competition between the firms. If the profits of the monopolist with marginal costs $c_{1}$ has a maximum for a price in $\left[c_{1}, c_{2}\right)$, then the strategy profiles in which Firm 1 chooses this price and Firm 2 chooses a strictly higher price are Nash equilibria and part of the MSS.

For each firm $i \in\{1,2\}$, its individual demand depends on its price $p_{i}$ and the price of its competitor $j \neq i$ and is given by:

$$
Q_{i}\left(p_{i}, p_{j}\right)= \begin{cases}D\left(p_{i}\right) & \text { if } p_{i}<p_{j} \\ D\left(p_{i}\right) / 2 & \text { if } p_{i}=p_{j} \\ 0 & \text { if } p_{i}>p_{j}\end{cases}
$$


Thus, the firm setting the lower price serves the entire market. In case of a tie, the market share of each firm equals $1 / 2$. For each firm $i \in\{1,2\}$, the demand $Q_{i}\left(p_{i}, p_{j}\right)$ leads to a payoff function $\pi_{i}: P_{1} \times P_{2} \longrightarrow \mathbb{R}$ defined by $\pi_{i}\left(p_{i}, p_{j}\right)=\left(p_{i}-c_{i}\right) Q_{i}\left(p_{i}, p_{j}\right)$.

The normal-form game $\left(\{1,2\},\left(P_{i}\right)_{i \in\{1,2\}},\left(\pi_{i}\right)_{i \in\{1,2\}}\right)$ is denoted by $\Gamma$.

\subsection{No Legal Restrictions}

The next result characterizes the unique MSS of the game. The set is illustrated as the shaded area in the left panel of Figure 1.

Proposition 4. The unique MSS of $\Gamma$ is given by:

$$
P^{*}=\left\{p \in P \mid c_{1} \leqslant p_{1} \leqslant \bar{p}_{\mathrm{m}} \text { and } p_{1} \leqslant p_{2}\right\} \cup\left\{p \in P \mid c_{2} \leqslant p_{2} \leqslant p_{1} \leqslant \bar{p}_{\mathrm{m}}\right\} \text {. }
$$

Proof. Let $M$ be an MSS.

Step 1. $P^{1}=\left\{p \in P \mid c_{1} \leqslant p_{1}=p_{2} \leqslant c_{2}\right\} \subseteq M$.

Towards a contradiction, suppose that $\left(p_{1}, p_{2}\right) \in P$ satisfies $c_{1}<p_{1}=p_{2}<c_{2}$ and $\left(p_{1}, p_{2}\right)$ is not in $M$. Once the contradiction is obtained, we get the result of Step 1 exploiting the fact that $M$ is closed.

Take some $p_{1}^{\prime} \in\left(c_{1}, p_{1}\right)$ and suppose that $\left(p_{1}^{\prime}, p_{2}\right) \in M$. Given that $\left(p_{1}, p_{2}\right) \notin M$ and $M$ is closed, there is an $\varepsilon^{\prime}>0$ such that for every $\varepsilon \in\left(0, \varepsilon^{\prime}\right)$ we have $\left(p_{1}-\varepsilon, p_{2}\right) \notin M$. However, for every $\varepsilon \in\left(0, \varepsilon^{\prime}\right)$, as the profits of a monopolist with marginal costs $c_{1}$ are strictly increasing on the domain $\left[c_{1}, c_{2}\right]$, Firm 1 will find it profitable to deviate to $p_{1}-\varepsilon>p^{\prime}$. Since $M$ satisfies deterrence of external deviations, it follows that $\left(p_{1}-\varepsilon, p_{2}\right) \in M$, leading to a contradiction. Consequently, it follows that for every $p_{1}^{\prime} \in\left(c_{1}, p_{1}\right),\left(p_{1}^{\prime}, p_{2}\right) \notin M$.

Take some $p_{1}^{\prime} \in\left(c_{1}, p_{1}\right)$ such that $\pi_{1}\left(p_{1}^{\prime}, p_{2}\right)>\pi_{1}\left(p_{1}, p_{2}\right) / 2$. It holds by the conclusion of the previous paragraph that $\left(p_{1}^{\prime}, p_{2}\right) \notin M$. By asymptotic external stability, there must be $\left(p_{1}^{\prime \prime}, p_{2}^{\prime \prime}\right) \in M$ such that $\left(p_{1}^{\prime \prime}, p_{2}^{\prime \prime}\right) \in f^{\infty}\left(p_{1}^{\prime}, p_{2}\right)$. Note that any profitable deviation of Firm 1 from $\left(p_{1}^{\prime}, p_{2}\right)$ is to a strategy profile $\left(\tilde{p}_{1}, p_{2}\right)$ such that $\tilde{p}_{1} \in\left(p_{1}^{\prime}, p_{1}\right)$. In any of these profiles, Firm 2 makes no sales and has no profitable deviation. Since none of these profiles is in $M$, by asymptotic external stability it holds that $\left(p_{1}, p_{2}\right) \in M$, a contradiction.

Step 2. $P^{2}=\left\{p \in P \mid c_{1} \leqslant p_{1} \leqslant c_{2}, p_{1} \leqslant p_{2}\right\} \subseteq M$.

Take $\left(p_{1}, p_{2}\right) \in P^{1}$ such that $p_{2}<c_{2}$. It follows from Step 1 that $\left(p_{1}, p_{2}\right) \in M$. It holds that $\pi_{2}\left(p_{1}, p_{2}\right)$ is strictly negative. As such, Firm 2 can gain by increasing $p_{2}$ to any value above $p_{1}$ resulting in a profit of zero. By deterrence of external deviations, all of 
these options must also be in $M$. The result of Step 2 now follows from the requirement that $M$ is closed.

Step 3. $P^{3}=\left\{p \in P \mid c_{2} \leqslant p_{1} \leqslant \bar{p}_{\mathrm{m}}, p_{1} \leqslant p_{2}\right\} \subseteq M$.

Take $\left(p_{1}, p_{2}\right) \in P^{2}$ such that $c_{1}=p_{1}<p_{2}$. By Step 2 it holds that $\left(p_{1}, p_{2}\right) \in M$. The profits of Firm 1 are equal to 0 . Then Firm 1 can deviate and increase profits by choosing $p_{1}^{\prime}$ such that $p_{1}<p_{1}^{\prime}<\bar{p}_{\mathrm{m}}$ and $p_{1}^{\prime}<p_{2}$. Since $M$ satisfies deterrence of external deviations, it holds that $\left(p_{1}^{\prime}, p_{2}\right) \in M$. Using closedness of $M$ we can again change strict inequalities to weak inequalities.

Step 4. $P^{4}=\left\{p \in P \mid c_{2} \leqslant p_{2} \leqslant p_{1} \leqslant \bar{p}_{\mathrm{m}}\right\} \subseteq M$.

Take $\left(p_{1}, p_{2}\right) \in P^{3}$ such that $c_{2}<p_{1}<\bar{p}_{\mathrm{m}}$ and $p_{1}<p_{2}$. By Step 3 it holds that $\left(p_{1}, p_{2}\right) \in M$. The profits of Firm 2 are equal to 0 . Now Firm 2 can deviate and set $p_{2}^{\prime}$ such that $c_{2}<p_{2}^{\prime}<p_{1}$ and make strictly positive profits. Again, the result of Step 4 follows by deterrence of external deviations and closedness of $M$.

Step 5. $P^{2} \cup P^{3} \cup P^{4}=P^{*}$ is the unique MSS.

First, observe that $P^{*}$ is closed. We have shown that $P^{*}$ is contained in any MSS, so we only need to show that $P^{*}$ itself satisfies deterrence of external deviations and asymptotic external stability. The set $P \backslash P^{*}$ is given by

$$
\underbrace{\left\{p \in P \mid p_{1} \leqslant p_{2}, p_{1}<c_{1}\right\}}_{P^{5}} \cup \underbrace{\left\{p \in P \mid p_{1}>p_{2}, p_{2}<c_{2}\right\}}_{P^{6}} \cup \underbrace{\left\{p \in P \mid p_{1}>\bar{p}_{\mathrm{m}}, p_{2} \geqslant c_{2}\right\}}_{P^{7}} .
$$

In order to see that $P^{*}$ satisfies deterrence of external deviations, note that Firm 1 makes non-negative profits at any strategy profile in $P^{*}$ and non-positive profits at any profile in $P \backslash P^{*}$. Thus, Firm 1 will never deviate from a strategy profile in $P^{*}$ to a strategy profile in $P \backslash P^{*}$. Next, Firm 2 cannot deviate to any strategy profile in $P^{5} \cup P^{7}$ from any strategy profile in $P^{*}$. Finally, at any strategy profile in $P^{6}$, Firm 2 has negative profits. Firm 2 only obtains negative profits at strategy profiles in $P^{*}$ if $p_{1}=p_{2}<c_{2}$. In these cases, if Firm 2 deviates to a profile in $P^{6}$ by choosing $p_{2}^{\prime}<p_{1}$, its profits decrease. Thus, Firm 2 will not make such a deviation.

It remains to be shown that $P^{*}$ satisfies asymptotic external stability. At any strategy profile in $P^{5}$, Firm 1 has a negative profit and the deviation to $\left(c_{1}, p_{2}\right)$ is thus profitable for Firm 1. If $p_{2} \geqslant c_{1}$ then $\left(c_{1}, p_{2}\right) \in P^{*}$, otherwise Firm 2 can gain by deviating to $\left(c_{1}, c_{2}\right) \in P^{*}$. In $P^{6}$, Firm 2 has a negative profit and the deviation to $\left(p_{1}, c_{2}\right)$ is profitable for Firm 2. If $p_{1} \geqslant c_{1}$ then $\left(p_{1}, c_{2}\right) \in P^{*}$. Otherwise, there exists a profitable deviation of Firm 1 to $\left(c_{1}, c_{2}\right) \in P^{*}$. In $P^{7}$, Firm 1 has a profit of at most zero. Thus, the deviation to the profile $\left(\left(c_{1}+c_{2}\right) / 2, p_{2}\right) \in P^{*}$ is profitable for Firm 1 . 
Figure 1: The MSS for the asymmetric Bertrand model. Left panel: without legal restrictions. Right panel: with legal restrictions.
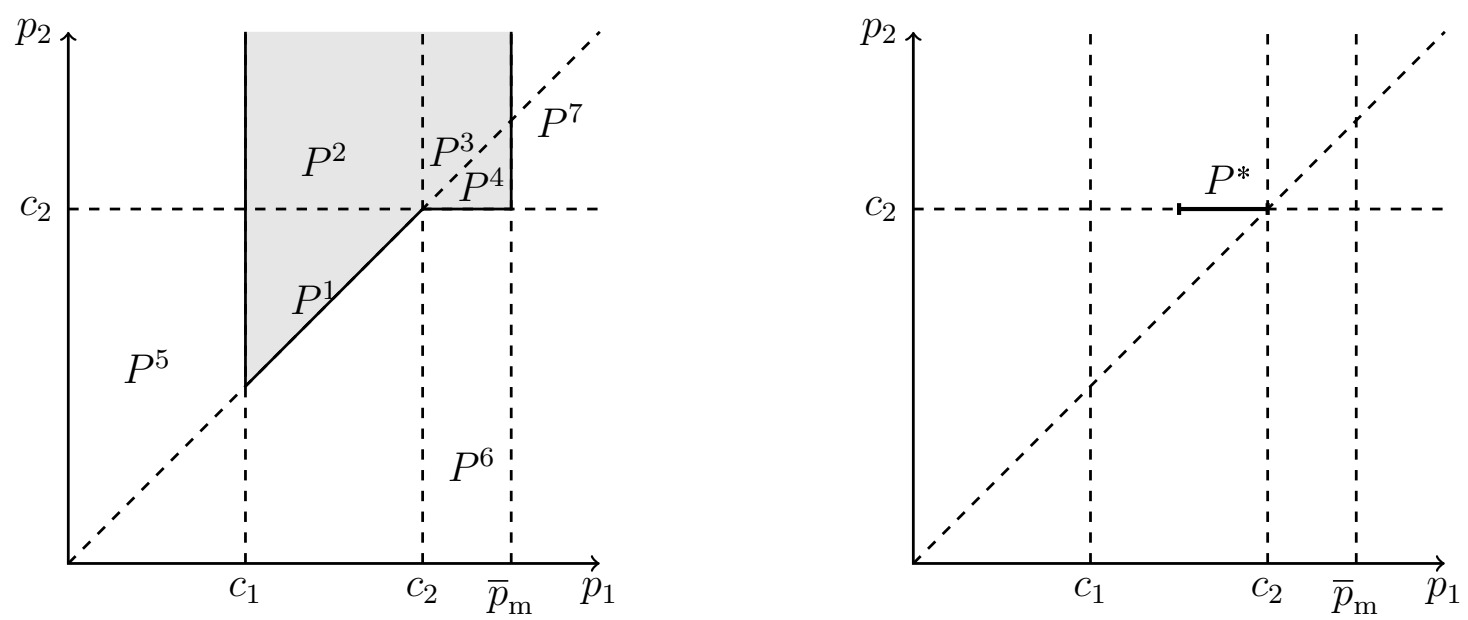

\subsection{Legal Restrictions on Predatory Pricing}

Let us now consider a slightly different version of Bertrand competition. In many countries, pricing below marginal or average cost is considered to be predatory pricing and is thus forbidden by law. We analyze how this restriction influences the MSS. To do so, we adjust the sets of strategies and define

$$
\begin{aligned}
& \tilde{P}_{1}=\left\{p_{1} \in P_{1} \mid p_{1} \geqslant c_{1}\right\}, \\
& \tilde{P}_{2}=\left\{p_{2} \in P_{2} \mid p_{2} \geqslant c_{2}\right\},
\end{aligned}
$$

and $\tilde{P}=\tilde{P}_{1} \times \tilde{P}_{2}$.

The absence of predatory pricing is similar to the requirement of undominated strategies in Kartik (2011). The only difference is that pricing at marginal costs is allowed in our setting, while it is ruled out in Kartik (2011). The normal-form game $\left(\{1,2\},\left(\tilde{P}_{i}\right)_{i \in\{1,2\}},\left(\pi_{i}\right)_{i \in\{1,2\}}\right)$ is denoted by $\tilde{\Gamma}$.

The following proposition shows that the MSS gets much smaller under legal restrictions on predatory pricing. Let $\underline{p}_{1} \in\left(c_{1}, c_{2}\right)$ be the uniquely determined price such that $\pi_{1}\left(\underline{p}_{1}, c_{2}\right)=$ $\pi_{1}\left(c_{2}, c_{2}\right)$.

Proposition 5. The unique MSS of $\tilde{\Gamma}$ is given by

$$
\tilde{P}^{*}=\left\{\left(p_{1}, p_{2}\right) \in \tilde{P} \mid \pi_{1}\left(p_{1}, c_{2}\right) \geqslant \pi_{1}\left(c_{2}, c_{2}\right), p_{2}=c_{2}\right\}=\left[\underline{p}_{1}, c_{2}\right] \times\left\{c_{2}\right\} .
$$

Proof. We split the proof into several steps.

Step 1. We show that $\tilde{P}^{*}$ satisfies deterrence of external deviations and asymptotic external stability. We start with deterrence of external deviations. For $\left(p_{1}, c_{2}\right) \in \tilde{P}^{*}$, profits of 
Firm 1 are greater than or equal to $\pi_{1}\left(c_{2}, c_{2}\right)$. For $p_{1} \notin\left[\underline{p}_{1}, c_{2}\right]$, profits are $\pi_{1}\left(p_{1}, c_{2}\right)<$ $\pi_{1}\left(c_{2}, c_{2}\right)$. Thus, for any state in $\tilde{P}^{*}$, player 1 will not deviate to a state in $\tilde{P} \backslash \tilde{P}^{*}$. Firm 2 makes zero profits for any point in $\tilde{P}^{*}$ and non-positive profits for any $p_{2} \in \tilde{P}_{2}$ if $p_{1} \leqslant c_{2}$. Thus, Firm 2 has no profitable deviation. This shows deterrence of external deviations for $\tilde{P}^{*}$.

It remains to verify asymptotic external stability. Let some $\left(p_{1}, p_{2}\right) \in \tilde{P} \backslash \tilde{P}^{*}$ be given. If $c_{2}<p_{1}<p_{2}$, then Firm 2 can profitably deviate to $p_{2}^{\prime}=\left(c_{2}+\min \left\{p_{1}, p_{\mathrm{m}}\right\}\right) / 2$ and Firm 1 can profitably deviate in the next step to $p_{1}^{\prime}=\left(c_{2}+p_{2}^{\prime}\right) / 2$ and so forth. It follows that $\left(c_{2}, c_{2}\right) \in f^{\infty}\left(p_{1}, p_{2}\right) \cap \tilde{P}^{*}$. If $p_{1} \leqslant c_{2}<p_{2}$, then Firm 1 can profitably deviate to $\left(p_{1}^{\prime}, p_{2}\right)$, where $p_{1}^{\prime} \in\left(c_{2}, p_{2}\right)$ is chosen such that $p_{1}^{\prime}<c_{2}+\varepsilon$ with $\varepsilon>0$ such that the profits $\left(p_{\mathrm{m}}-c_{1}\right) D\left(p_{\mathrm{m}}\right)$ of a monopolist with marginal costs $c_{1}$ are strictly increasing in $p_{\mathrm{m}}$ on the domain $\left[c_{1}, c_{2}+\varepsilon\right]$. We can then continue as in the previous case. If $c_{2}<p_{2} \leqslant p_{1}$, then there is $p_{1}^{\prime} \in\left(c_{2}, p_{2}\right)$ such that $\pi_{1}\left(p_{1}^{\prime}, p_{2}\right)>\pi_{1}\left(p_{1}, p_{2}\right)$. Either $p_{2} \leqslant \bar{p}_{\mathrm{m}}$ and $p_{1}^{\prime}$ is obtained by slightly undercutting $p_{2}$, or $p_{2}>\bar{p}_{m}$ and any $p_{1}^{\prime} \in\left(c_{2}, \bar{p}_{\mathrm{m}}\right)$ will do. Now we can continue as before. If $p_{1} \notin\left[\underline{p}_{1}, c_{2}\right]$ and $p_{2}=c_{2}$, then Firm 1 can profitably deviate to $c_{2}$ to reach a strategy profile in $\tilde{P}^{*}$. Because of the legal restrictions on predatory pricing, we have covered all strategy profiles in $\tilde{P} \backslash \tilde{P}^{*}$ and thereby shown that $\tilde{P}^{*}$ satisfies asymptotic external stability.

Step 2. Let $M \subseteq \tilde{P}^{*}$ be a set satisfying deterrence of external deviations and asymptotic external stability. Let us show that for every $p_{1} \in\left[\underline{p}_{1}, c_{2}\right)$ it holds that $\left(p_{1}, c_{2}\right) \in M$ implies $\left(c_{2}, c_{2}\right) \in M$. Suppose $\left(p_{1}, c_{2}\right) \in M$ and $\left(c_{2}, c_{2}\right) \notin M$. By closedness of $M$, there is $\varepsilon^{\prime}>0$ such that, for every $\varepsilon \in\left(0, \varepsilon^{\prime}\right),\left(c_{2}-\varepsilon, c_{2}\right) \notin M$. Take $p_{1}^{\prime}=\max \left\{\left(p_{1}+c_{2}\right) / 2, c_{2}-\right.$ $\left.\varepsilon^{\prime} / 2\right\}$, then $\left(p_{1}^{\prime}, c_{2}\right) \in f\left(p_{1}, c_{2}\right)$, so $\left(p_{1}^{\prime}, c_{2}\right) \in M$. Given that $p_{1}^{\prime}>c_{2}-\varepsilon^{\prime}$, we obtain a contradiction.

Step 3. Let $M \subseteq \tilde{P}^{*}$ be a set satisfying deterrence of external deviations and asymptotic external stability. Let us show that if $\left(c_{2}, c_{2}\right) \in M$, then, for every $p_{1} \in\left[\underline{p}_{1}, c_{2}\right)$, we have $\left(p_{1}, c_{2}\right) \in M$. This follows from the fact that, for every $p_{1} \in\left(\underline{p}_{1}, c_{2}\right), \pi_{1}\left(p_{1}, c_{2}\right)>$ $\pi_{1}\left(c_{2}, c_{2}\right)$ and the fact that $M$ is closed.

Step 4. We are now ready to show that $\tilde{P}^{*}$ is an MSS. First of all, by Step 1 it satisfies deterrence of external deviations and asymptotic external stability. So if $\tilde{P}^{*}$ is not an MSS, it should violate minimality. This means that there is a proper subset $M$ of $\tilde{P}^{*}$ that also satisfies deterrence of external deviations and asymptotic external stability. The set $M$ either contains $\left(c_{2}, c_{2}\right)$ or it is a subset of $\left[p_{1}, c_{2}\right) \times\left\{c_{2}\right\}$. If $M$ contains $\left(c_{2}, c_{2}\right)$ then, by Step 3, it should contain $\left[\underline{p}_{1}, c_{2}\right) \times\left\{c_{2}\right\}$ and therefore be equal to $\tilde{P}^{*}$, a contradiction with $M$ being a proper subset of $\tilde{P}^{*}$. If $M$ is a subset of $\tilde{P}^{*} \backslash\left\{\left(c_{2}, c_{2}\right)\right\}$, then by Step 2 , it should contain $\left(c_{2}, c_{2}\right)$, a contradiction. 
Step 5. Finally we show that $\tilde{P}^{*}$ is the unique MSS. Let $M$ be an MSS. We show that $\tilde{P}^{*} \cap M \neq$ $\varnothing$. Towards a contradiction, suppose that $\tilde{P}^{*} \cap M=\varnothing$. Then, for all $p^{\prime} \in \tilde{P}^{*}$, there is $p^{\prime \prime} \in M$ such that $p^{\prime \prime} \in f^{\infty}\left(p^{\prime}\right)$. Given that $\tilde{P}^{*}$ is closed and $p^{\prime \prime} \notin \tilde{P}^{*}$, there is $\varepsilon>0$ such that $B_{\varepsilon}\left(p^{\prime \prime}\right) \cap \tilde{P}^{*}=\varnothing$, where $B_{\varepsilon}\left(p^{\prime \prime}\right)=\left\{p \in \tilde{P} \mid d\left(p, p^{\prime \prime}\right)<\varepsilon\right\}$. By definition of $f^{\infty}$, there is $k \in \mathbb{N}$ and $p \in \tilde{P}$ such that $p \in f^{k}\left(p^{\prime}\right)$ and $p \in B_{\varepsilon}\left(p^{\prime \prime}\right)$. By a $k$-fold application of deterrence of external deviations, it holds that $p \in \tilde{P}^{*}$, so $p \in B_{\varepsilon}\left(p^{\prime \prime}\right) \cap \tilde{P}^{*}$ and we have obtained a contradiction. Consequently, it holds that $\tilde{P}^{*} \cap M \neq \varnothing$.

Step 6. If $M$ contains $\left(c_{2}, c_{2}\right)$, then, by Step 3, $M$ should also contain $\tilde{P}^{*} \backslash\left\{\left(c_{2}, c_{2}\right)\right\}$, so $\tilde{P}^{*} \subseteq M$ and by minimality $\tilde{P}^{*}=M$. If $M$ contains an element of $\tilde{P}^{*} \backslash\left\{\left(c_{2}, c_{2}\right)\right\}$, then, by Step 2 , it should also contain $\left(c_{2}, c_{2}\right)$ and, by Step 3, also $\tilde{P}^{*} \backslash\left\{\left(c_{2}, c_{2}\right)\right\}$. Again, we obtain $\tilde{P}^{*} \subseteq M$ and by minimality $\tilde{P}^{*}=M$.

\section{Discussion}

We have provided a complete characterization of the Myopic Stable Set for two versions of the Bertrand duopoly with asymmetric marginal costs. Despite the popularity of Bertrand competition, the set of Nash equilibria has not been fully characterized and, without a restriction to undominated strategies, even no equivalence of equilibrium payoffs has been established.

For our solution concept, we obtain a unique set-valued prediction both when predatory pricing is allowed and when it is forbidden by law. A clean solution to a game with such a complex set of Nash equilibria boosts the appeal of the Myopic Stable Set.

Another implication of our results is that when predatory pricing is forbidden, the market price is predicted to be weakly lower than in Nash equilibria in undominated strategies.

\section{References}

Bertrand, J. (1883), "Review of 'Théorie Mathématique de la Richesse Sociale' and 'Recherches sur les Principes Mathématiques de la Théorie des Richesses"', Journal des Savants, 67, 499-508.

Blume, A. (2003), "Bertrand without Fudge," Economics Letters, 78, 167-168.

Chwe, M. S.-Y. (1994), "Farsighted Coalitional Stability," Journal of Economic Theory, 63, 299-325.

Demuynck, T., P.J.J. Herings, R.D. Saulle, and C. Seel (2018), "The Myopic Stable Set for Social Environments," GSBE Research Memorandum 18/001, Maastricht University, Maastricht, pp. $1-49$.

Kartik, N. (2011), "A Note on Undominated Bertrand Equilibria," Economics Letters, 111, 125-126. 